\title{
A METHOD FOR TYPING SHIGELLA SONNEI, USING COLICINE PRODUCTION AS A MARKER
}

\author{
BY \\ J. D. ABBOTT AND R. SHANNON \\ From the Public Health Laboratory, Manchester
}

(RECEIVED FOR PUBLICATION APRIL 25, 1957)

Infection with Shigella sonnei is the most common identifiable cause of diarrhoea in this country at present, and the absence of a satisfactory method of typing the organism has greatly hampered the study of its mode of spread. Bojlén (1934), studying the biochemical reactions of 1,786 Sonne cultures, isolated from 741 patients in Denmark, described four biochemical types based upon the fermentation of maltose and xylose. However, when these cultures were examined at a later date only xylose fermentation was found to be stable. Although other workers (Cruickshank and Swyer, 1940 ; Tee, 1955) found xylose fermentation useful for tracing Sonne infections, the method has only a limited value in this country ; for example, Tee (1955) examined cultures from 812 patients and found that only $44(5.4 \%)$ fermented xylose.

Phage-typing of $S$. sonnei was first reported by Hammarström (1947) in Sweden, and appears to have proved useful to some workers (Ludford, 1953 ; Szturm-Rubinsten and Thibault, 1956). In this country the method was used by Mayr-Harting (1952) and by Tee (1955). The latter, who tested 829 Sonne cultures with 10 unadapted phages, concluded: "This method of phage-typing, because of evidence of type instability and because the majority of strains belong to the same phage-type, has little practical value as a routine procedure in the control of Sonne dysentery in this country."

Davies (1954) described a simple disc technique for testing Sonne cultures for sulphonamide sensitivity. Strains isolated from family or institutional outbreaks were usually either all sensitive or all resistant ; in outbreaks where mixed infections occurred there was evidence of multiple sources of infection. Occasionally, exacting strains were found. which required for normal growth the addition of one or more amino-acids to the synthetic medium used for testing the sensitivity to sulphonamides by this method. The dependence upon one or more amino-acids may be used as a "marker" for tracing infection with exacting strains.

None of these procedures has proved entirely satisfactory because no procedure has divided the species into a sufficient number of commonly encountered types.

Fredericq (1946a) tested the sensitivity of a number of non-lactose-fermenting intestinal bacteria, including Salmonellae and Shigellae, to antibacterial substances produced by two strains of Escherichia coli and one aerobic spore-bearing bacillus, and showed that they could be divided into groups by means of their pattern of susceptibility to these substances. He suggested that it might be possible to establish for each type of organism a characteristic "antibiotic sensitivity formula" analogous to the antigenic formula already established for members of the Salmonella group. This work led us to investigate the sensitivity of Sonne strains to colicines to see if this property could be used as a basis for a typing method.

\section{Materials and Methods}

Media.-The following were used :

Infusion Broth.-A beef infusion to which $1 \%$ peptone (Evans) and $0.5 \%$ sodium chloride were added, and the $p \mathrm{H}$ adjusted to 7.4-7.6 (Mackie and McCartney, 1948).

Nutrient Agar.-One per cent. New Zealand agar (Davis) was incorporated in infusion broth.

Lab-Lemco Agar.-One per cent. New Zealand agar (Davis) was incorporated in Lab-Lemco infusion broth (Mackie and McCartney, 1948), and the final $p \mathrm{H}$ adjusted to 7.4-7.6.

Blood Agar.-Ten per cent. horse blood was incorporated in nutrient agar or Lab-Lemco agar.

Dorset's egg medium was prepared according to the formula of Mackie and McCartney (1948). 
MacConkey agar was prepared according to the formula of the Ministry of Health (1956).

Incubation.-Incubation was aerobic at $35^{\circ} \mathrm{C}$. to $36^{\circ} \mathrm{C}$.

Identification of Cultures.-All strains of $S$. sonnei were plated out on to MacConkey's agar and their identity confirmed by colonial morphology and slide agglutination with S-R Sonne antiserum (Standards Laboratory).

Maintenance of Cultures.-Cultures were stored on Dorset's egg medium in screw-capped bottles at room temperature in the dark.

Sulphonamide Sensitivity Tests. - The method described by Davies (1954) was used.

Testing for Colicine Production.-A simple method was devised by one of us for testing Esch. coli O55 B5 cultures for colicine production and for sensitivity to colicines (Shannon, 1957). This method, a modification of one used by Fredericq, Thibault, and Gratia (1946), was found to be suitable also for $S$. sonnei. The culture to be tested for colicine activity (the active strain) was inoculated heavily from MacConkey agar across a dried blood-agar plate to give a confluent streak of growth (the primary streak); the purpose of the horse blood was to act as a source of catalase to eliminate inhibition due to hydrogen peroxide formation (Gardner, 1950). After a suitable period of incubation, the active strain was killed by exposure to chloroform. For this purpose a disc of filter paper was placed in the lid of a Petri dish and saturated with chloroform, the portion containing the medium was replaced and the plate left inverted on the bench. After one hour's exposure to chloroform vapour, the growth was scraped to one end with the edge of a clean slide and then removed together with a small portion of agar. More chloroform was added to keep the filter paper moist and the plate was left closed for a further hour on the bench. The filter paper was then removed, and the plate exposed to the air on the bench for three hours with the lid open and the surface of the medium face down. Overnight broth cultures of organisms to be tested for sensitivity to colicines (the passive or indicator strains) were then inoculated across the plate at right angles to the position formerly occupied by the primary streak. The passive strains were inoculated with a 3-4 $\mathrm{mm}$. loop so as to give a regular confluent growth across the plate. When inoculating a large number of plates, it was found unnecessary to flame the loop between each plate; it was sufficient to flame the loop before it was introduced into a broth culture of a different organism. The plates were incubated overnight and examined the next day.

If no colicine active against any of the passive strains was produced, all grew across the plate as parallel confluent streaks. If such a colicine was produced, areas of inhibition of one or more of the passive strains were seen, distributed symmetrically on either side of the original line of inoculation of the active strain.
The results were read as follows:

$$
\begin{aligned}
&++=\text { Inhibition zone }>4 \mathrm{~mm} . \\
&++=\quad, \quad, \quad 2-4 \mathrm{~mm} . \\
&+=20 \text { mm. } \\
& \pm=\text { Thinning only } \\
& \bar{R}=\text { No inhibition } \\
& \mathrm{R}=\text { Presence of numerous resistant } \\
& \text { colonies in zone of inhibition } \\
& \mathrm{D}=\mathrm{A} \text { characteristic form of inhibition } \\
& \text { consisting of a central area of growth } \\
& \text { with a zone of inhibition on either } \\
& \text { side. }
\end{aligned}
$$

Thus, $+++R$ indicates a wide zone of inhibition with numerous resistant colonies, and $++D$ a central plateau of growth with a moderate zone of inhibition on either side. In reading the results, the width of inhibition zones was not measured accurately but estimated approximately.

This technique of testing colicine production was used in all the experiments, although the incubation period of the primary streak and the composition of the blood-agar medium were varied.

\section{Preliminary Investigation}

Lab-Lemco blood-agar plates were used in these tests ; the primary streak (active strain) was incubated for 48 hours before exposure to chloroform vapour.

Sensitivity of S. sonnei to Colicines. - It seemed possible that $S$. sonnei cultures might be divided into groups by means of their susceptibility to colicines produced by other organisms.

Therefore, 50 Esch. coli cultures isolated from routine faecal specimens were tested for colicine activity against 46 Sonne strains that had been sent from various parts of England. Fifteen of the Esch. coli cultures produced colicines; some inhibited all 46 Sonne cultures, while others inhibited only a few. The 15 active Esch. coli cultures were then tested against a number of epidemiologically related Sonne strains. Different sensitivity patterns were often shown by strains that were considered identical from epidemiological evidence.

Next, each of the 46 Sonne strains were tested for colicine activity against itself and against the other 45 Sonne strains. The results confirmed the work of Fredericq (1948a), who found that many Sonne cultures were active against other Sonne cultures, although a particular strain was never sensitive to its own colicine. The sensitivity of groups of epidemiologically related cultures to the colicines produced by a number of active strains was then tested. Once again, strains that might have been expected on epidemiological grounds to be identical often showed different sensitivity patterns.

It was unlikely, therefore, that the sensitivity patterns of Sonne strains to colicines could be 
used as a basis for a typing method, since related strains often differed in their sensitivity to colicines produced by cultures of Esch. coli or S. sonnei.

Production of Colicines by Shigella sonnei.The preceding experiments had shown that $S$. sonnei cultures frequently produced colicines active against other strains of $S$. sonnei. We therefore investigated the production of colicines by Sonne strains to find out whether this property could be used as a basis for a typing method.

A number of related Sonne strains were tested for the production of colicines active against a series of passive (indicator) strains selected from the 46 Sonne cultures used in the previous experiments. The results were encouraging, since cultures considered identical from epidemiological evidence produced colicines active against the same indicator strains. Moreover, consistent results were obtained when the tests were repeated.

\section{The Inhibition Patterns Produced by Sonne Cultures on Selected Indicator Strains}

Lab-Lemco blood-agar medium was used; the period of incubation of the primary streak was extended to four days, as certain Sonne strains (type 2) produced weak and variable inhibition zones after two days' incubation. From the 46 Sonne cultures used in the previous experiments, six indicator strains which divided certain Sonne cultures into types by means of clear-cut inhibition zones were selected; indicator strains giving variable results, or inhibition zones that were weak or overgrown with resistant variants, were rejected.

One hundred Sonne cultures, mostly isolated in the Manchester area, were tested for colicine activity against the six indicator strains. Over a half of the 100 Sonne cultures could be classified into one of three types according to the inhibition patterns produced upon the indicator organisms. The inhibition patterns of the three types are shown in Table I. The commonest type was type 1 , type 2 was found less frequently, and type 3

TABLE I

INHIBITION PATTERNS OF TYPABLE STRAINS OF S. SONNEI ON SIX INDICATOR STRAINS

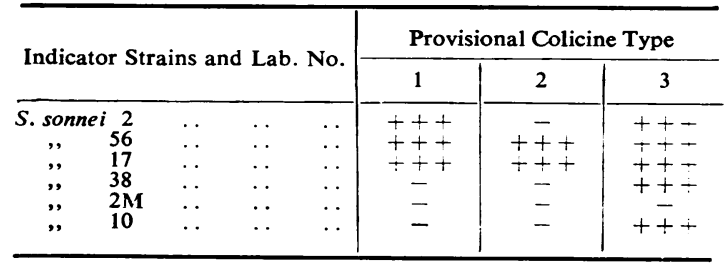

cultures were isolated on three occasions only. The remaining cultures were classed as untypable ; these included some strains that inhibited none of the indicator strains and others giving inhibition patterns different from those shown in Table $I$.

Stability of Indicator Strains. - Indicator strains were maintained on Dorset's egg medium with infrequent subculture, and stored at room temperature in the dark. With one exception$S$. sonnei 10 -the sensitivity of the indicator strains remained stable over a period of several months. S. sonnei 10 was later discarded since its sensitivity to type 1 cultures varied slightly in successive tests. The stability of these indicator strains confirms the work of Fredericq (1948b), who found that the sensitivity or resistance of a culture to a particular colicine was usually stable ; the sensitivity of certain strains that were tested by him many times over a period of four years remained the same.

Stability of Colicine Production.-Fredericq (1948b) showed that colicine production is a stable property. It is usually unaffected by changes in morphology, in biochemical reactions, or in antigenic structure-such as S-R variation (Fredericq, 1946b). Our experiments confirmed these findings ; Sonne cultures produced similar inhibition patterns when tests were repeated many times over a period of several months; colicine production was unaffected by changes in colonial morphology.

Consistency of Typing Results.-Reproducible results were obtained when cultures were tested over a period of several months. A number of different colonies of $S$. sonnei selected from the primary cultures of faeces on deoxycholate-citrate agar were tested for colicine production. An average of six colonies from primary cultures of nine type 1 strains were examined, and all gave similar inhibition patterns. Repeated isolations from the same patient were tested on a number of occasions, with identical results. In view of these encouraging results, attempts were made to type a further series of Sonne strains, using a similar, but slightly modified, technique.

\section{Typing of 537 Sonne Strains by Means of Colicine Production}

Layered blood-agar plates made with nutrient agar were used instead of Lab-Lemco blood-agar. The period of incubation of the primary streak was reduced from four to three days, since satisfactory inhibition zones were obtained after three days' incubation on the nutrient agar medium. 
The source of the Sonne cultures examined was as follows:

\begin{tabular}{|c|c|c|}
\hline $\begin{array}{l}\text { Public Health Laboratory, } \\
\text { Manchester } \\
\text { Public Health Laboratory, }\end{array}$ & 314 & strair \\
\hline & 142 & , \\
\hline $\begin{array}{ccc}\text { Wakefield } & \ldots & \ldots \\
\text { Other laboratories } & \ldots & \ldots\end{array}$ & $\begin{array}{l}50 \\
31\end{array}$ & ", \\
\hline
\end{tabular}

Indicator Strains.-The number of indicator organisms was increased to 14 . These comprised five of the cultures-S. sonnei $2,56,17,2 \mathrm{M}$ and 38-that had been used previously (Table I), one culture of $S$. schmitzi N.C.T.C. No. 8218-and a further eight strains obtained by selecting resistant variants of some of the five Sonne cultures. Fredericq (1947) classified colicines produced by Esch. coli and $S$. sonnei by their action upon a carefully selected series of resistant variants. He showed also that resistant variants usually retain their resistance indefinitely; for instance, some resistant mutants retained their resistance after 300 subcultures, although others occasionally recovered some of their original sensitivity (Fredericq, 1948b). By selecting resistant colonies from the inhibition zones of some of the indicator strains, and using these resistant variants as indicator organisms, we were able to provide new indicator strains to check the identity of known colicine types and to distinguish new colicine types. Once again, we selected only those cultures that gave clear-cut reproducible reactions of value in distinguishing the different types. The source from which the resistant variants were derived is shown in Table II. In

TABLE II

SOURCE OF RESISTANT VARIANTS USED AS INDICATOR STRAINS

\begin{tabular}{|c|c|c|}
\hline $\begin{array}{l}\text { Indicator Strains } \\
\text { and Lab. No. }\end{array}$ & $\begin{array}{c}\text { Indicator Strain from } \\
\text { which Resistant } \\
\text { Colony was Selected }\end{array}$ & $\begin{array}{l}\text { Provisional Colicine } \\
\text { Type of Active Strain } \\
\text { to which Selected } \\
\text { Colony was Resistant }\end{array}$ \\
\hline $\begin{array}{cl}\text { S. sonnei } & 5656 \\
\text {, } & 5698 \\
., & \text { R1 } \\
., & \text { R6 } \\
,, & 27 \\
, & 264 \\
, & 2,15 \\
, . & \text { R5 }\end{array}$ & $\begin{array}{r}56 \\
56 \\
2 \\
56 \\
2 \\
2 \\
2 \\
27\end{array}$ & $\begin{array}{c}2 \\
2 \\
1 \mathrm{~b} \\
1 \mathrm{a} \\
1 \mathrm{a} \\
\text { Untypable } \\
1 \mathrm{a} \\
5\end{array}$ \\
\hline
\end{tabular}

addition, each of the Sonne cultures used as an indicator organism was itself tested for colicine production. The results of typing these organisms are shown in Table III. As the work of Fredericq (1948c) would lead one to expect, each of the resistant variants produced the same inhibition patterns as the parent strain. The sensitivity or resistance to colicines of the 14 indicator organisms remained unaltered over a period of 12 months.
TABLE III

PROVISIONAL COLICINE TYPE OF SONNE CULTURES USED AS INDICATOR STRAINS

\begin{tabular}{|c|c|c|}
\hline Indicato & trains and Lab. No. & Provisional Colicine Type \\
\hline $\begin{array}{rc}\text { S. sonnei } 2, \mathrm{R} \\
,, & 56, \\
,, & 17 \\
,, & 2 \mathrm{M} \\
,, & 38\end{array}$ & 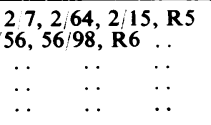 & $\begin{array}{c}2 \\
\text { Untypable } \\
\ddot{3} \\
1 \mathrm{~b}\end{array}$ \\
\hline
\end{tabular}

Colicine Types.-By means of the inhibition patterns produced upon the 14 indicator organisms, two-thirds of the Sonne cultures could be divided into seven colicine types (Table IV); each of the

TABLE IV

INHIBITION PATTERNS OF TYPABLE STRAINS OF $S$. SONNEI ON 14 INDICATOR STRAINS

\begin{tabular}{|c|c|c|c|c|c|c|c|}
\hline \multirow{2}{*}{$\begin{array}{c}\text { Indicator Strains } \\
\text { and } \\
\text { Lab. No. }\end{array}$} & \multicolumn{7}{|c|}{ Provisional Colicine Type } \\
\hline & $1 \mathrm{a}$ & $1 b$ & 2 & 3 & 4 & 5 & 6 \\
\hline 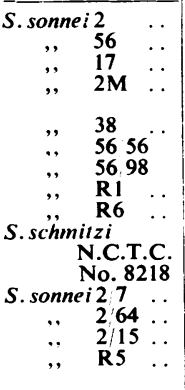 & $\begin{array}{c}- \\
+++ \\
+++ \\
- \\
- \\
+++ \\
\text { or }++ \\
-\end{array}$ & $\begin{array}{c}+++ \\
+++ \\
++ \\
- \\
\ldots \\
+++ \\
+++ \\
+++ \\
+++ \\
\text { or }+ \\
-\end{array} \mid$ & $\left\{\begin{array}{c}- \\
+++ \\
++ \\
- \\
- \\
- \\
- \\
++ \\
- \\
- \\
-\end{array}\right.$ & $\begin{array}{c}t+t \\
+++ \\
+++ \\
- \\
+++ \\
+++ \\
++t \\
+++ \\
+++ \\
+++ \\
+++ \\
+++ \\
+++ \\
++\end{array}$ & $\left\{\begin{array}{c}t+t \\
++t \\
++t \\
- \\
\text { or } \\
++t \\
- \\
- \\
+++ \\
+++ \\
\\
+++ \\
+++ \\
++\end{array}\right.$ & $\begin{array}{l}+++ \\
+++ \\
+++ \\
- \\
\text { or } \\
+++ \\
+++ \\
+++ \\
+++ \\
+++ \\
++- \\
\text { or }+- \\
++ \\
+++ \\
++\end{array}$ & $\begin{array}{c}+++ \\
- \\
- \\
++- \\
++ \\
+++\end{array}$ \\
\hline
\end{tabular}

seven types gave characteristic reactions which were reproduced when tests were repeated. Three $\dot{0}$ new types $(4,5$, and 6$)$ were added to the three previously distinguished, and type 1 was sub- $\delta$ divided into types $1 \mathrm{a}$ and $1 \mathrm{~b}$ by the reaction of the indicator organism R6. The inhibition pattern 웅

TABLE V

TYPING RESULTS OF 537 STRAINS OF $S$. SONNEI

\begin{tabular}{|c|c|c|c|c|c|c|c|c|c|c|}
\hline & \multirow{2}{*}{$\begin{array}{l}\text { Sulphon- } \\
\text { amide } \\
\text { Sensi- } \\
\text { tivity }\end{array}$} & \multicolumn{8}{|c|}{ Provisional Colicine Type } & \multirow{2}{*}{ 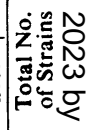 } \\
\hline & & $1 \mathrm{a}$ & $1 \mathrm{~b}$ & 2 & 3 & 4 & 5 & 6 & 这。 & \\
\hline $\begin{array}{l}\text { No. of strains iso- } \\
\text { lated from family } \\
\text { outbreaks }\end{array}$ & $\begin{array}{l}\text { Sensitive } \\
\text { Resistant } \\
\text { Exacting }\end{array}$ & $\overline{10}$ & $\overline{30}$ & $\begin{array}{l}41 \\
45 \\
10\end{array}$ & 二 & $\begin{array}{r}6 \\
4 \\
- \\
\end{array}$ & $\frac{-9}{-}$ & $\frac{-}{6}$ & $\begin{array}{r}29 \\
14 \\
1\end{array}$ & $\begin{array}{r}76 \\
118 \stackrel{5}{\mathbb{D}} \\
11 \stackrel{?}{?}\end{array}$ \\
\hline $\begin{array}{l}\text { No. of strains iso- } \\
\text { lated from insti- } \\
\text { tutional out- } \\
\text { breaks }\end{array}$ & $\begin{array}{l}\text { Sensitive } \\
\text { Resistant } \\
\text { Exacting }\end{array}$ & $\frac{21}{-}$ & $\overline{44}$ & $\begin{array}{r}31 \\
20 \\
9\end{array}$ & $\frac{-}{2}$ & $\begin{array}{r}11 \\
3 \\
-\end{array}$ & $\frac{-}{4}$ & $\overline{-}$ & $\begin{array}{l}63 \\
15 \\
-\end{array}$ & 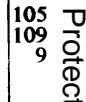 \\
\hline $\begin{array}{l}\text { No. of other } \\
\text { strains }\end{array}$ & $\begin{array}{l}\text { Sensitive } \\
\text { Resistant } \\
\text { Exacting }\end{array}$ & $\frac{-}{3}$ & 10 & $\begin{array}{r}12 \\
8 \\
7\end{array}$ & 1 & $\frac{-3}{-}$ & $\frac{7}{-}$ & $\begin{array}{r}2 \\
6 \\
- \\
\end{array}$ & $\begin{array}{r}33 \\
14 \\
1\end{array}$ & $\begin{array}{l}47 \text { व } \\
54 \text { Q } \\
8 \text { O }\end{array}$ \\
\hline \multicolumn{2}{|c|}{ Total No. of strains } & 34 & 84 & 183 & 3 & 27 & 22 & 14 & 170 & 537 \\
\hline
\end{tabular}



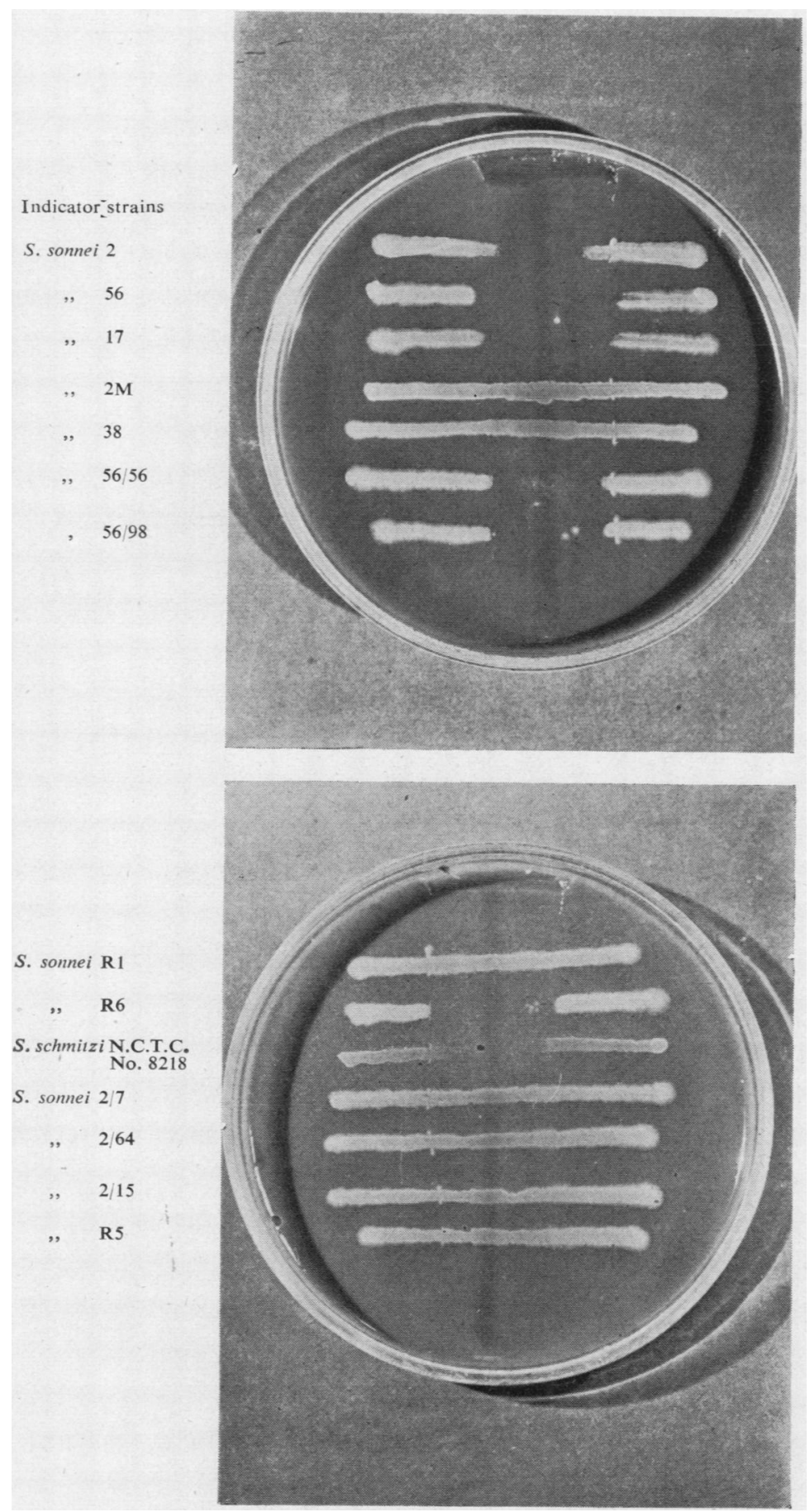

FIG. 1.-The inhibit ion pattern produced by a strain of $S$. sonnei of colicine type $1 \mathrm{~b}$ on the 14 indicator strains. produced by a type $1 \mathrm{~b}$ strain is shown in Fig. 1. The remaining one-third of the Sonne cultures, classified as untypable, included. strains with no action on any of the indicator organisms, a nd other strains giving variable results or inhibition patterns different from those shown in Table IV. The production of colicines by the seven colicine types appears to be stable. A number of strains of each type was re-examined after six months' storage on Dorset's egg medium, and gave similar inhibition patterns to when they were first tested. There is some evidence, however, that cultures stored for longer periods may show weaker reactions. As some of the indicator strains give identical reactions, it would be possible to distinguish the seven types with fewer than 14 indicator organisms. At present, however, we are continuing to use the full series of indicator strains, to detect possible variations in sensitivity of the indicator organisms and to increase the chance of recognizing new types. Two blood-agar plates are therefore needed to type each culture, with seven indicator strains on each plate.

Results.-From March to September, 1956, 537 Sonne cultures were tested for colicine production and for sulphonamide sensitivity ; 367 were classified into one of the seven colicine types and $\mathbf{1 7 0}$ were untypable (Table V). Approximately one-third of the cultures belonged to type 2 , one-third were untypable, and the remaining one-third comprised members of the other six types.

The relationship of the colicine types to sulphon- 
amide sensitivity is also shown in Table V. It is of interest that all strains of types $1 \mathrm{a}, 1 \mathrm{~b}, 3$, and 5 were resistant to sulphonamide.

One hundred and thirty-four outbreaks were investigated. In this context we define an outbreak as two or more isolations of $S$. sonnei within a period of four weeks from different persons in a family or institution. The colicine type was uniform in 97 outbreaks (306 out of 456 strains) and mixed in five (18 out of 456 strains) ; in 32 outbreaks the strains were untypable (132 out of 456 strains). The sulphonamide sensitivity was uniform in 127 outbreaks (431 out of 456 strains) and mixed in seven ( 25 out of 456 strains). The distribution of colicine types and sulphonamide sensitivity in the outbreaks with uniform colicine type and sulphonamide sensitivity is shown in Table VI. We have also included in this table outbreaks

TABLE VI

DISTRIBUTION OF COLICINE TYPE AND SULPHONAMIDE SENSITIVITY IN OUTBREAKS WITH $S$. SONNEI STRAINS OF UNIFORM COLICINE TYPE AND SULPHONAMIDE SENSITIVITY*

\begin{tabular}{|c|c|c|c|c|c|c|c|c|c|c|}
\hline & \multirow{2}{*}{$\begin{array}{l}\text { Sulphon- } \\
\text { an.ide } \\
\text { Sensi- } \\
\text { tivity }\end{array}$} & \multicolumn{8}{|c|}{ Provisional Colicine Type } & \multirow{2}{*}{ 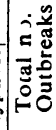 } \\
\hline & & $1 \mathrm{a}$ & $1 \mathrm{~b}$ & 2 & 3 & 4 & 5 & 6 & 这 & \\
\hline $\begin{array}{l}\text { No. of out- } \\
\text { breaks in } \\
\text { families }\end{array}$ & $\begin{array}{l}\text { Sensitive } \\
\text { Resistant } \\
\text { Exacting }\end{array}$ & -4 & $\frac{1}{-}$ & $\begin{array}{r}17 \\
18 \\
3\end{array}$ & - & $\begin{array}{r}3 \\
2 \\
-\end{array}$ & $\overline{4}$ & 2 & $\begin{array}{r}9 \\
5 \\
-\end{array}$ & $\begin{array}{r}29 \\
44 \\
3\end{array}$ \\
\hline $\begin{array}{l}\text { No. of out- } \\
\text { breaks in } \\
\text { institutions }\end{array}$ & $\begin{array}{l}\text { Sensitive } \\
\text { Resistant } \\
\text { Exacting }\end{array}$ & $\overline{4}$ & $\frac{\overline{8}}{-}$ & $\begin{array}{l}9 \\
5 \\
2\end{array}$ & 1 & $\begin{array}{r}4 \\
1 \\
-\end{array}$ & - & 二 & $\begin{array}{r}13 \\
2 \\
-\end{array}$ & $\begin{array}{r}26 \\
22 \\
2\end{array}$ \\
\hline \multicolumn{2}{|c|}{ Total no. of outbreaks } & 8 & 17 & 54 & 1 & 10 & 5 & 2 & 29 & 126 \\
\hline
\end{tabular}

*Outbreaks with untypable strains of uniform sulphonamide sensitivity are also included.

with untypable strains which were of uniform sulphonamide sensitivity. Type 2 strains were found in about half of the outbreaks, untypable strains in a quarter, and other colicine types in the remainder. From the number of uniform outbreaks with type 1a, 1b, 2, 4, and 5 strains, it seems probable that these correspond to genuine epidemiological types; the number of infections with type 3 and type 6 strains is, as yet, too few to assess their value as epidemiological types.

The distribution of colicine types and sulphonamide sensitivity in the mixed outbreaks is shown in Table VII. These comprised four with mixed colicine type and mixed sulphonamide sensitivity, and one with mixed colicine type and uniform sulphonamide sensitivity; in three outbreaks the sulphonamide sensitivity was mixed but the strains were untypable. It seems likely that outbreaks with mixed colicine types represent true mixed infections, rather than instability of colicine types, as they were few and usually associated with a difference in sulphonamide sensitivity.

TABLE VII

DISTRIBUTION OF COLICINE TYPE AND SULPHONAMIDE SENSITIVITY IN “ MIXED " OUTBREAKS

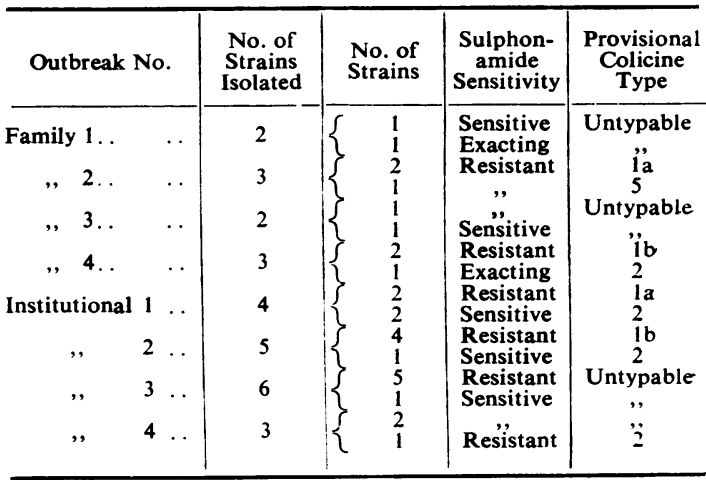

\section{Discussion}

The distribution of strains amongst the different colicine types compares favourably with phagetyping methods. Tee (1955), who examined 829 Sonne cultures by a phage-typing method, found that $74 \%$ belonged to one phage type. About twothirds of the cultures tested could be typed, and the commonest type, type 2 , constituted only $29 \%$ of all cultures tested.

Colicine typing gave reliable epidemiological information. In 97 of the 102 outbreaks from which typable strains were isolated the colicine type was uniform, and the results were in agreement with the epidemiological evidence. In four of the five outbreaks from which strains of different colicine types were isolated there was also a difference in sulphonamide sensitivity. A small number of mixed outbreaks might be expected with such a common infection as Sonne dysentery.

At present the main disadvantage of the method is the large number of untypable strains, in this series approximately a third of all cultures examined. It may prove possible in the future to reduce this number. Of the 170 strains that were untypable, 126 gave consistently negative results against the 14 indicator strains. If further work confirms that these $\mathbf{1 2 6}$ strains are completely inert, and if they can be clearly distinguished from other untypable strains, some of which produce very weak reactions, it may be possible to classify the inert strains into one group.

Further work is necessary to standardize the conditions of the test. The best results have been obtained by incubating the primary streak for three 
days on blood-agar medium prepared with infusion broth. The activity of type 6 strains, in particular, is affected by small changes in the composition of the medium. The optimum temperature of incubation appears to be $35^{\circ}$ C. $-36^{\circ}$ C. Variable results are obtained at lower temperatures, and at higher temperatures the inhibition zones are less clear cut.

It is possible that the detection of colicine production may form the basis of typing systems for other organisms. One of us has had success with a similar technique for typing Esch. coli O55 B5.

\section{Summary}

(1) The sensitivity of $S$. sonnei to colicines was investigated. It seemed unlikely that colicine sensitivity could be used as a basis for a typing method since the sensitivity of epidemiologically related strains often differed.

(2) A method of typing strains of $S$. sonnei by means of colicine production was described. Strains were divided into types by the inhibition patterns produced upon a series of selected indicator organisms. Related strains produced colicines active against the same indicator organism.

(3) Of 537 cultures of $S$. sonnei examined by this method, 367 were classified into one of seven colicine types and 170 were untypable. The cultures were also tested for sensitivity to sulphonamides.

(4) One hundred and thirty-four outbreaks were investigated. The colicine type was uniform in 97 and mixed in five ; in 32 outbreaks the strains were untypable. The sulphonamide sensitivity was uniform in 127 outbreaks and mixed in seven. The outbreaks with mixed colicine type probably represent true mixed outbreaks rather than examples of instability of colicine types.

(5) The method is technically simple, and gives reproducible results. Its value would be enhanced if it proves possible to reduce the number of untypable strains.

We wish to thank Dr. M. T. Parker for encouraging us to undertake this investigation and for much helpful advice. We are also grateful to Dr. A. J. H. Tomlinson and Dr. L. A. Little for cultures and for their advice and help, and to Miss J. Perry for the photographs.

\section{REFERENCES}

Bojlén, K. (1934). Dysentery in Denmark. Copenhagen. Cruickshank, R., and Swyer, R. (1940). Lancet, 2, 803.

Davies, J. R. (1954). Monthly Bull. Minist. Hlth (Lond.), 13, 114.

Fredericq, P. (1946a). C. R. Soc. Biol. (Paris), 140, 1133.

- (1946b). Ibid., 140, 1057.

-_ (1947). Bull. Soc. Chim. biol. (Paris), $29,358$.

- (1948a). C. R. Soc. Biol. (Paris), 142, 399.

- (1948b). Rev. belge Path., 19, Suppl. 4, p. 53.

- (1948c). Ibid., p. 51.

- Thibault, J., and Gratia, A. (1946). C. R. Soc. Biol. (Paris), 140, 1035.

Gardner, J. F. (1950). Brit. J. exp. Path., 31, 102.

Hammarström, E. (1947). Lancet, 1, 102.

Ludford, C. G. (1953). Aust. J. exp. Biol. med. Sci., 31, 545.

Mackie, T. J., and McCartney, J. E. (1948). Handbook of Practical Bacteriology, 8th ed. Livingstone, Edinburgh.

Mayr-Harting, A. (1952). J. gen. Microbiol., 7, 382.

Ministry of Health (1956). Reports on Public Health and Medical - Subjects, No. 71, 3rd ed. H.M.S.O., London.

Shannon, R. (1957). J. med. Lab. Technol., 14, 199.

Szturm-Rubinsten, S., and Thibault, P. (1956). Bull Acad. nat. Méd. (Paris), 140, 51 .

Tee, G. H. (1955). J. Hyg. (Lond.), 53, 54. 